\title{
Ambiente de la isla Roqueta de Acapulco Guerrero, México
}

\author{
Naú Silverio Niño Gutiérrez
}

RESUMEN

La Geografía del ambiente de la isla La Roqueta de Acapulco implica analizar las condiciones actuales del paisaje insular para proponer su posible manejo sustentable como área natural protegida para lo cual se incluye la elaboración de las cartas geográficas temáticas de localización, litológica, altimétrica, edafológica, uso actual del suelo y vegetación.

PALABRAS CLAVE

Geografía, Ambiente, Manejo ambiental, Isla La Roqueta, Acapulco. 


\title{
Ambiente de la isla Roqueta de Acapulco Guerrero, México
}

\author{
Naú Silverio Niño Gutiérrez
}

ABSTRACT

To apply the Geography features to The Roqueta island's environment in Acapulco will allow us to analyze the present conditions of the insular landscape so as to propose its supporting management like a protected natural area. The making of geographic locating charts by themes is included; these themes are lithology, altimetry, soil-studying, present-soil use and vegetation. We suggest the future-environmental managing.

\section{KEY WORDS}

Geography, Environment, Environmental Management, The Roqueta Island, Acapulco. 


\section{INTRODUCCIÓN}

Guerrero posee gran riqueza físico-biológica que genera bienes y servicios ambientales a través de su biodiversidad y espacios silvestres. Ello ha motivado el estudio de La Roqueta, con la finalidad de que sea un ecosistema donde se privilegien procesos de desarrollo sustentable en la zona contigua a la Ciudad y Puerto de Acapulco.

El objetivo central del trabajo expone las características físicas, bióticas y antrópicas que interactúan en La Roqueta a fin de sintetizar las condiciones que potencialmente contribuyen a mejorar el ambiente natural de la isla.

Se justifica realizar este estudio porque permite ofrecer una visión holista de los factores que facultan la gestión ambiental de un enclave geográfico de importancia internacional desde el punto de vista turístico pero que también lo puede ser desde el aspecto ecológico.

Naú Silverio Niño

Gutiérrez

Doctor en Geografia y

Doctorante en Ciencias Ambientales.

Profesor-Investigador Titular

de Tiempo Completo, Centro

de Investigación y Posgrado

en Estudios Socioterritoriales

(CIPES), Universidad

Autónoma de Guerrero.

Teléfono y fax:

01-74-41-26-30-44

e-mail:

nausilverio@yahoo.com.mx, zurit76@hotmail.com 
ANTECEDENTES

La isla de La Roqueta fue decretada como Parque Nacional Marino en el año de 1982 durante la administración del entonces Presidente de la República Lic. José López Portillo la cual quedó bajo la vigilancia y resguardo directo de la Secretaría de Marina, el aspecto turístico quedó a cargo de la Secretaría de Turismo del estado de Guerrero dependencia que elaboraría su plan turístico y sus programas con el propósito de integrar a ésta isla al proceso de planificación turística nacional. Sin embargo, actualmente ostenta la categoría de Unidad de Manejo Ambiental (UMA), quien es atendida de manera coordinada entre las Direcciones de Turismo y Ecología del Municipio de Acapulco.

La isla aunque muy conocida por el turismo nacional y extranjero de sol y playa está poco estudiada desde el punto de vista geográfico motivo por el cual se procedió a indagar las características que integran a los marcos físiconatural y socioeconómico locales.

Los resultados que se presentan a la fecha forman parte del proyecto de investigación "Diagnóstico ecogeográfico del paisaje terrestre de la isla La Roqueta de Acapulco, Guerrero 1948-2008" registrado en la Dirección de Investigación Científica de la Universidad Autónoma de Guerrero (UAG) y que se desarrolla en la Línea de Generación y Aplicación del Conocimiento (LGAC) en Ambiente, sociedad y sustentabilidad del Centro de Investigación y Posgrado en Estudios Socioterritoriales (CIPES).

Se hizo la revisión de las guías turísticas municipales, estatales de la Secretaría de Turismo, la carta topográfica Acapulco E14C57 versión 2005 a escala 1:50 000 del Instituto Nacional de Estadística Geografía e Informática (INEGI); las Memorias de Acapulco, Martínez (1994) además de algunos avances del autor publicados en las memorias in extenso en el VI Congreso Internacional y XII Nacional de Ciencias Ambientales de 2007. 
El estudio se inició a principios del año 2007 y las bases de datos que se presentan abarcan de 2003 a la fecha en las que se observa a las actividades económicas practicadas de manera anárquica en el ambiente marino de La Roqueta y Canal Boca Chica y por tanto ponen en riesgo la permanencia de los recursos hídricos, geomorfológicos, flora y fauna, en parte por la falta de una adecuada planificación socioterritorial que faculte a los pobladores locales satisfacer sus necesidades básicas y coexistir con los recursos naturales que le rodean (Melo y Niño 2006: 30-45).

Otro trabajo que en materia geográfica brinda la caracterización del ambiente de La Roqueta es el trabajo de Niño (2007), donde se exponen los recursos naturales como soportes del ecoturismo. Sustentado en el análisis de la Carta Topográfica de Acapulco E14C57, escala 1:50 000 del INEGI, 2005 entre otros. 


\section{METODOLOGÍA}

Se sustenta en trabajo de gabinete y campo, en el primer caso se hizo revisión de archivos, libros, revistas, páginas Web de la Internet en el Centro de Investigación y Posgrado en Estudios Socioterritoriales (CIPES), de la Universidad Autónoma de Guerrero; consulta y análisis de datos estadísticos impresos, bases de datos digitales, interpretación de cartas geográficas, ortofoto de la bahía de Acapulco en la sede del INEGI; en tanto que, el segundo comprendió observación directa que implicó ocho recorridos exploratorios entre 2006 y 2007 que permitieron entrevistas con lancheros, pescadores, concesionarios, ambientalistas y autoridades municipales encargadas de la ecología y turismo de Acapulco, Guerrero; además de tomas fotográficas.

En este sentido el enfoque empleado es multimodal o mixto ya que se conjugan los puntos de vista cualitativos y cuantitativos a fin de ofrecer un panorama integral de las características ambientales y el aprovechamiento actual que hace el hombre de los recursos naturales de La Roqueta. 


\section{DESARROLLO}

La importancia de la Geografía física en el presente documento resalta en la medida que lleva a establecer las características actuales de la vegetación principalmente, pero sin dejar de lado, los recursos: agua y suelo, ya que dichos elementos son aprovechados con fines turísticos. En este sentido, se observa la relevancia del uso actual del suelo del ecosistema terrestre para caminatas y excursionismo mientras que en el ecosistema marino se desarrollan actividades recreativas activas como son natación, buceo, snorquel, viajes en lancha, velerismo, pesca deportiva entre otras.

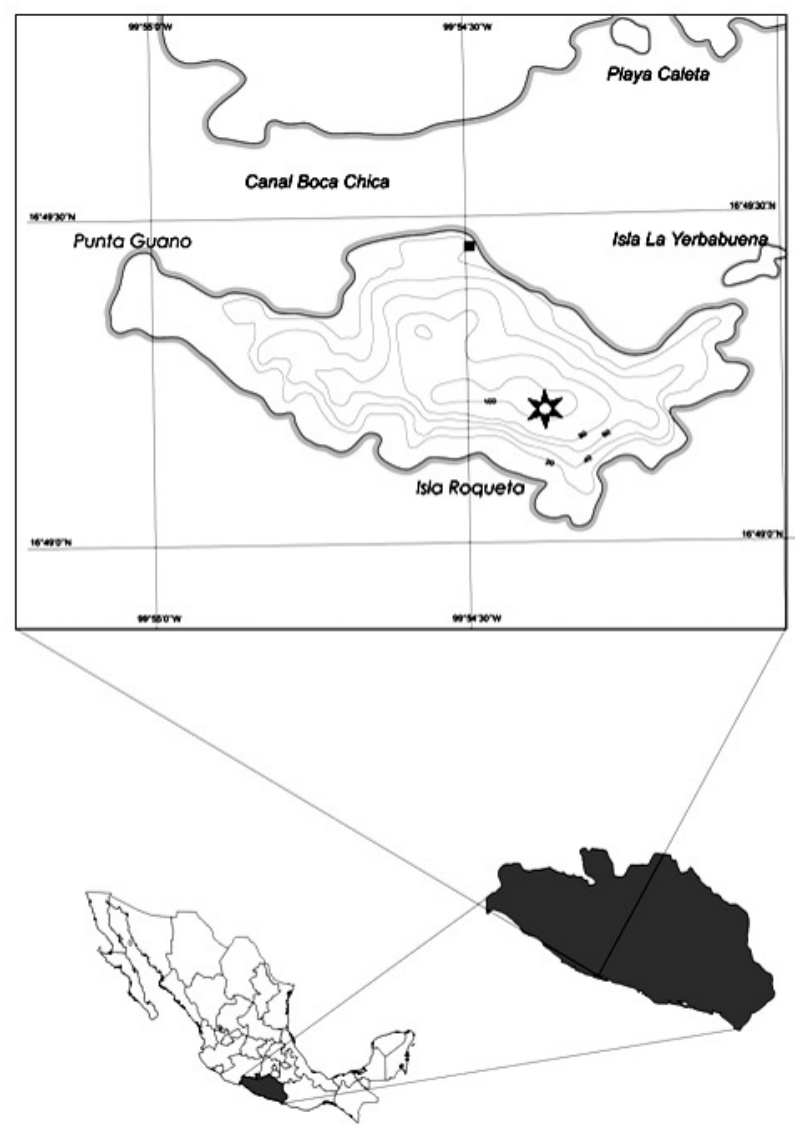

Guerrero está dividido en siete regiones económicas a saber: Acapulco, Costa Grande, Costa Chica, Centro, Norte, Tierra Caliente y La Montaña. Es precisamente, en Acapulco donde se encuentra ubicada la isla Roqueta en la porción sur de la Bahía de Santa Lucía. La Roqueta se localiza al suroeste de la bahía de Acapulco, entre las coordenadas geográficas $16^{\circ} 49^{\prime} 30^{\prime \prime}$ a $16^{\circ} 49^{\prime} 02^{\prime \prime}$ de Latitud Norte y $99^{\circ} 54^{\prime} 03^{\prime \prime}$ a $99^{\circ} 55^{\prime} 07^{\prime \prime}$ de Longitud Oeste. Ostenta longitud lineal oeste-este de 1,700 m, amplitud norte-sur de $730 \mathrm{~m}$ y altura de $120 \mathrm{~m}$, abarca 75 ha, vecinas a La Roqueta se encuentran la microisla "El Morro" y la isla La Hierbabuena (INEGl, 2005:1) (Figura 1). 


\section{GEOGRAFÍA FÍSICA}

Es la rama de la geografía general que comprende los elementos de la naturaleza como geología, litología, geomorfología, clima, suelo y agua. La vía de acceso para llegar a la isla es el Canal Boca Chica de un kilómetro de longitud y profundidad media de $15 \mathrm{~m}$. La porción sur de La Roqueta presenta acantilados de fuerte pendiente que se proyectan hacia el mar donde el oleaje nulifica toda presencia de playas. En cambio, la porción norte cuenta con acantilados de pendientes moderadas, semiprotegida por el oleaje que da como resultado la existencia de una playa conocida como "Ensenada las Palmitas".

Desde el punto de vista de la Geología, La Roqueta se ubica en los límites de la Placa Norteamericana y las subplacas de Cocos y Nazca por lo que, el tectonismo es muy activo. Es precisamente Acapulco una zona de subducción donde la placa continental se introduce hacia la placa oceánica con lo cual se tiene una zona sísmica muy activa.

Hipsométricamente La Roqueta está conformada por las zonas: montañosa, de piedemonte y de Planicie aluvial lo cual se relaciona fuertemente con el factor pendiente de tal manera que la zona montañosa: Comprende todo el afloramiento insular a partir de la cota ubicada en $0 \mathrm{msnm}$ pero inferior a los $125 \mathrm{msnm}$. Sus componentes físicos predominantes le confieren relieve con gama variable de pendientes moderadas y fuertes con clima cálido suhúmedo.

El relieve montañoso, exhibe pendientes fuertes, el área restante correspondiente a paisajes de laderas está dominada por pendientes moderadas. Los rangos de inclinación llana, débil y moderada concurren en paisajes del piedemonte. La pendiente es un factor limitante para los asentamientos humanos y, por otro lado, favorece los procesos erosivos y pérdida del suelo. La zona de piedemonte: comprende gran franja transicional que establece contacto con la zona montañosa y la planicie aluvial. Ostenta piso altimétrico de 5 a $100 \mathrm{msnm}$, manifiesta pendientes moderadas y fuertes.

Zona de planicie aluvial: Comprende terreno deprimido de los alrededores de la isla su altitud va de 1 a 2 msnm, le imprime pendiente general llana y condición climática tropical subhúmeda. De acuerdo con su carácter receptor de aguas fluviales y acumulación de material transportado. 
Se presenta la erosión hídrica laminar producto de la morfología accidentada del relieve y las condiciones edáficas antes mencionadas, la ocurrencia de meteoros pluviales (lluvias) y atmosféricos (vientos), que actúan sobre los terrenos desprovistos de cubierta vegetal, intensifican la dinámica de procesos erosivos que ocasionan frecuente pérdida de suelos bajo las modalidades hídrica y eólica. Por la presencia cerril la gran mayoría de paisajes experimentan escaso grado de erosión hídrica laminar durante la época húmeda del año.

La Roqueta está conformada por rocas ígneas, integradas por gneis y esquistos (INEGI, 2004:4), en general son rocas difíciles de erosionar aún ante la presencia de oleaje fuerte. Pero, también hay rocas sedimentarias que resultan de la pulverización a través del tiempo de gneis y esquistos locales de ahí la presencia de las playas del norte de La Roqueta. La geomorfología tiene que ver con las diversas formas del terreno como son elevaciones, seguidas de escasas "mesetas", pie de monte o laderas cerriles y diminuta planicie aluvial. Las pendientes en La Roqueta rebasan los $45^{\circ}$ por lo que, es difícil observar construcciones. Desde el punto de vista geomorfológico se ubica en la planicie aluvial de la Llanura Costera del Océano Pacífico.

El clima es cálido subhúmedo con lluvias en verano (Aw1). Las lluvias torrenciales se presentan durante el verano entre los meses de Mayo a Noviembre. El promedio de días nublados es de 72 al año. La oscilación térmica es de $0.6^{\circ} \mathrm{C}$ entre $26.5^{\circ} \mathrm{C}$ y $27.1^{\circ} \mathrm{C}$. La temperatura media anual es de $26.5^{\circ} \mathrm{C}$. Donde la presencia del mar juega un papel importante como regulador térmico local (Vidal, 2005:173).

Los vientos dominantes tienen dirección oeste-suroeste en los meses de enero a junio y sólo del oeste-noroeste en los meses agosto, octubre y noviembre, presentan velocidad entre 2.52 y 8.64 $\mathrm{Km} / \mathrm{h}$. Periodo en el que se presentan los ciclones debido a que el continente ostenta mayor temperatura y menor presión y el Océano menor temperatura y mayor presión por lo que, el viento se desplaza del mar hacia la tierra firme, según la primera ley de Buys-Ballot que expresa que los vientos se desplazan de la alta a la baja presión (Fabián y Escobar, 2002:241). 
En la isla hay 15 arroyos cuyo recorrido es corto además brotan aguas subterráneas en forma de manantiales, que se aprovechan para abrevaderos de animales silvestres. Por su situación geográfica y características naturales, la isla La Roqueta constituye un medio de gran valor natural; sin embargo, la actividad pesquera realizada de forma irracional puede modificar sustancialmente el entorno causando graves impactos a nivel local, con serias repercusiones sociales.

La hidrografía superficial se reduce a la presencia de arroyos que se activan en la época lluviosa del año. Alrededor de la isla, tiene fuerte presencia el oleaje marino local que alcanza altura promedio de $75 \mathrm{~cm}$ sobre la superficie del agua en periodos de 13 segundos.

El suelo: Litosol se expresa a través de afloramientos rocosos, ligeramente ácido, bajo contenido de materia orgánica y capacidad agrícola nula. Por lo que, su vocación natural es para vida silvestre ya que sustenta vegetación con mínimas necesidades edáficas. Aunque también, se reconocen los suelos aluviales y Regosol eútrico además de Cambisol eútrico, Phaeozem háplico, con buena proporción de materia orgánica, aunque poco poroso, limitada permeabilidad y escasamente drenado, además de suelo Solonchak salino que marca la interfase mar tierra.

Las asociaciones de suelos son tres, en orden de mayor distribución espacial aparece la que se encuentra conformada por Feozem háplico-Cambisol eútrico, seguido de la asociación Regosol eútrico-Litosol y finalmente Solonchak gléyico-Regosol eútrico. Lo cual, establece la potencialidad de la zona para vida silvestre como sucede en los terrenos altos y relativamente bajos. La Roqueta tiene amalgama de coberturas vegetales medias, altas y muy altas, producto de regulares y bajos niveles deforestativos. El resto de unidades paisajísticas onduladas exhiben baja y nula cubierta vegetal por efecto de la constante deforestación. La vocación natural del sector cerril es de aptitud forestal; mientras que la planicie, funciona como vaso colector de escurrimientos fluviales, con desarrollo de vegetación riparia y crecimiento de pastos halófilos (Figura 2). 
Figura 2

Unidades y asociaciones de suelos

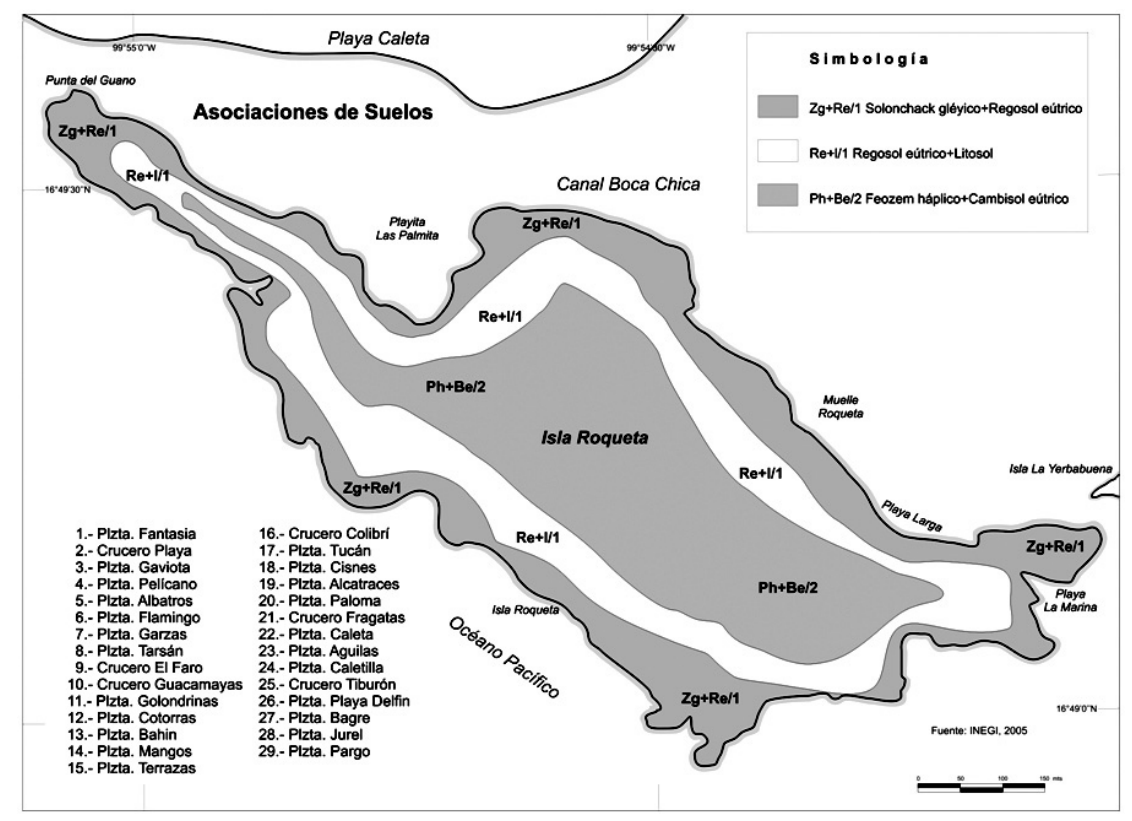

Fuente: INEGI, 2005. 


\section{GEOBIOLOGÍA}

Es la rama de la Geografía que se encarga del estudio, características y distribución espacial de las plantas y los animales. La vegetación natural está integrada por selva baja caducifolia y subcaducifolia: cedro, matorral rosetófilo, palmas y bejucos. La unidad cerril ostenta el menor nivel de alteración por lo que mantiene funcionamiento ecológico óptimo y opera como zona de alta captación pluvial, infiltración hídrica y recarga de mantos acuíferos. Además, la unidad contiene importante valor paisajístico otorgado por su capacidad escénica y amplitud visual gracias a la presencia de importantes núcleos selváticos, por lo cual, ofrece amplias posibilidades para el fomento y desarrollo de múltiples actividades recreativas, programas educativo-ambientales e investigaciones ecológicas.

Las porciones de piedemonte y aluvial, son las que resienten escasas transformaciones en sus componentes naturales, ya que han experimentado mínimo cambio reflejado en la perturbación de la vegetación primaria.

Las condiciones físico-geográficas de la parte cerril de la isla aún se conservan, lo cual ejerce un enorme beneficio sobre la misma por fungir como regulador térmico y ser ideal para la vida silvestre por lo que, es necesaria su protección. El ecosistema marino y sus particulares características en cuanto a relieve, suelos, vegetación, clima, flora y fauna, han favorecido el usufructo de las aguas aledañas a la isla; sin embargo, la anarquía con la que se realizan las actividades turísticas recreativas intensivas y pesqueras ha modificado las condiciones naturales de manera moderada.

La fauna terrestre se integra por iguana negra (Ctenosaura pectinata), verde (Iguana iguana), lagartija cola de látigo (Cnemidophorus tigris), armadillo (Dasypus novemcinctus), tejón (Nasua narica), tlacuache (Didelphys marsupiales), mapache (Procyon lotor), venado cola blanca (Odocoileus virginianus), búho real (Bubo virginianus), zopilote rey (Sarcoramphus papa), calandria de agua (Icterus cucullatus), urraca hermosa cara blanca (Calocitta formosa), ardilla arbórea (Sciurus poliopus). La fauna de carácter marino comprende tortugas marinas laud (Dermochelys coriacea), golfina (Lepidochelys olivácea); moluscos, coral cerebro (Diploria strigosa) y peces (Araujo, 2003:37-110). 


\section{GEOGRAFÍA DE LA POBLACIÓN}

Es la rama de la geografía que auxilia en la explicación de las características de las personas, la concentración total en un territorio, edad, sexo, etcétera. La población asentada permanentemente es de 10 personas que son vigilantes en los tres restaurantes que hay emplazados en la isla, más sesenta que fungen como boleteros, cocineros, ambientadores, meseras y más de 600 en promedio quienes son turistas flotantes que visitan a la isla diariamente.

La infraestructura local se compone de andadores, miradores, líneas de conducción aérea e instalaciones especiales. Los andadores privilegian la comunicación terrestre a través de toda la isla por lo que, construyeron miradores naturales para mejor visualización del mar abierto. Las líneas eléctricas que existen suministran el servicio en los Restaurantes y en el área del Faro, dichas instalaciones especiales se retroalimentan con pequeñas represas y dos pozos artificiales que fueron construidos con el objetivo de que la fauna silvestre tome agua dulce. 


\section{GEOGRAFÍA TURÍSTICA}

Es la parte de la geografía económica que estudia al turismo nacional y extranjero de sol y playa y otros tipos de turismo alternativo. El desarrollo turístico de La Roqueta se remonta al año 1948 cuando empiezan los trabajos del Restaurant Palao y embarcaciones fondo de cristal que transportaban a los turistas desde el Canal Boca Chica de Caleta y Caletilla a la isla. También opera otro restaurante cuyos dueños son cuatro concesionarios. Las lanchas que proveen el servicio de transporte a la isla son 45 manipuladas por integrantes de dos cooperativas locales.

Los concesionarios de La Roqueta realizan importantes tareas de conservación y promoción como destino turístico ecológico, a fin de incrementar sus posibilidades de sobrevivencia en el mercado o incluso ganar posiciones de mercado y situarse hoy por hoy como líderes en él, sobre la base del desarrollo de un producto que incluye show prehispánico, clavado, admiración de peces multicolores, barra libre y buffete lo que redunda en una experiencia única concebida para responder a las demandas del turismo social nacional proveniente principalmente del D. F. (48.3\%), Estado de México (23.6\%), Morelos (11.5\%), Puebla (3.5\%), Querétaro (2.1\%), Ciudades de Guerrero (1.4\%), Hidalgo-Michoacán (1.2\%), según reveló una encuesta practicada a 506 personas en 2003 (UAG, 2003:7).

El turismo que llega a La Roqueta todavía no es una amenaza ya que la mayor parte de los visitantes se quedan en las playas de la isla, por lo que la afluencia hacia la selva es mínima y se reduce a profesionistas, estudiantes, académicas, etc. A la fecha no ponen en serio riesgo la conservación de este geosistema.

La Roqueta es apoyada actualmente por la Secretaría de Ecología Municipal de Acapulco y junto con los integrantes de la Sociedad Ecológica y Pro-Defensa de la Isla La Roqueta A.C., sustentados en el Programa Nacional de Turismo 2001-2006 que en el eje rector 3: Destinos sustentables plantea como objetivo 10: apoyar el desarrollo turístico, municipal, estatal y regional, centrado en el programa de playa están contempladas líneas estratégicas como: La conservación de playas como las de Palao y La Fantasía (Aviléz et al, 2003: 31). 
Recientemente, en el año 2005 una empresa denominada Acaextremo pretendía realizar un megaproyecto de desarrollo turístico en la isla pero afortunadamente fue detenido debido a la organización oportuna de la sociedad civil acapulqueña quienes se opusieron terminantemente a quienes pretendan instalar excesiva infraestructura en La Roqueta, porque ello demerita la calidad del paisaje, la belleza del pulmón verde de la ciudad o controlar la biodiversidad de esta zona donde confluye biota terrestre y marina. 


\section{GEOGRAFÍA DE LA PESCA}

Parte de la geografía económica que se encarga de analizar las causas y consecuencias de la pesca de subsistencia y alta mar. La Actividad de pesca local que se caracteriza por la utilización de artes de pesca manuales o de baja tecnología (por ejemplo, chinchorros, atarrayas, tendales) y que principalmente se desarrolla en zonas de poca profundidad de los cuerpos acuáticos. La pesca artesanal, se asocia a estratos socioeconómicos bajos y aun cercanos al nivel se subsistencia en los países en desarrollo. La diversidad de técnicas de captura en estos sistemas dificulta su caracterización, aunque es distintiva la escasa mecanización, el uso de reducidos capitales y mayor empleo de mano de obra.

La pesca artesanal incluye captura de sierra, jurel, robalo, marlín, pez vela, tiburón gata, recolección de almejas, cayo de hacha, ostiones y mejillones. Se ubica geográficamente en áreas que difieren enormemente en cuanto a las características de sus cuerpos de agua y del entorno, incluyendo al pescador artesanal como tal y a su familia. En este caso se habla de la pesca artesanal marinocostera. El tipo de arte de pesca comúnmente utilizada por los pescadores sugiere que el tipo de pesca practicada en la isla, tiene una tendencia hacia el comercio interno. De igual manera nos sugiere que esta actividad se desarrolla de manera colectiva. El ámbito marino que considera el rango de cero msnm de La Roqueta se ubica a los arrecifes coralinos, circunstancia natural que comparado con el ecosistema terrestre ostenta escasa representación. 


\section{RESULTADOS}

La interrelación de los factores físicos, bióticos y antrópicos llevan a un amalgamiento de atributos escénicos, sumados a funciones ecológicas, preserva el ecosistema de selva baja caducifolia, valiosa por su riqueza en biodiversidad florística y faunística; estos atributos operan como importante zona de captación pluvial y elevada recarga acuífera útil para mantener el equilibrio hidrológico local, y coadyuvan a la regulación y estabilidad climática.

Desde el punto de vista cualitativo se observa que el impacto de las actividades turísticas recreativas intensivas y pasivas ejercen modificaciones mínimas en el ecosistema terrestre y sólo se aprecian impactos medios en playas las Palmitas, la playa Larga y Palao, precisamente en la interfase mar-tierra (Figura 3).

La vegetación actualmente se encuentra relativamente alterada en las cercanías del Faro y el AcaZoo sin embargo, la isla ostenta valor ambiental alto donde se aprecian los estratos arbóreos bien conservados; valor medio en aquellos sitios donde hay cierta alteración de la vegetación como sucede en la playa La Marina y valor bajo en donde existe infraestructura turística dedicada a la venta de alimentos y bebidas como son los casos de los Restaurantes Palao y La Fantasía.

Figura 2

Uso actual del suelo

y vegetación

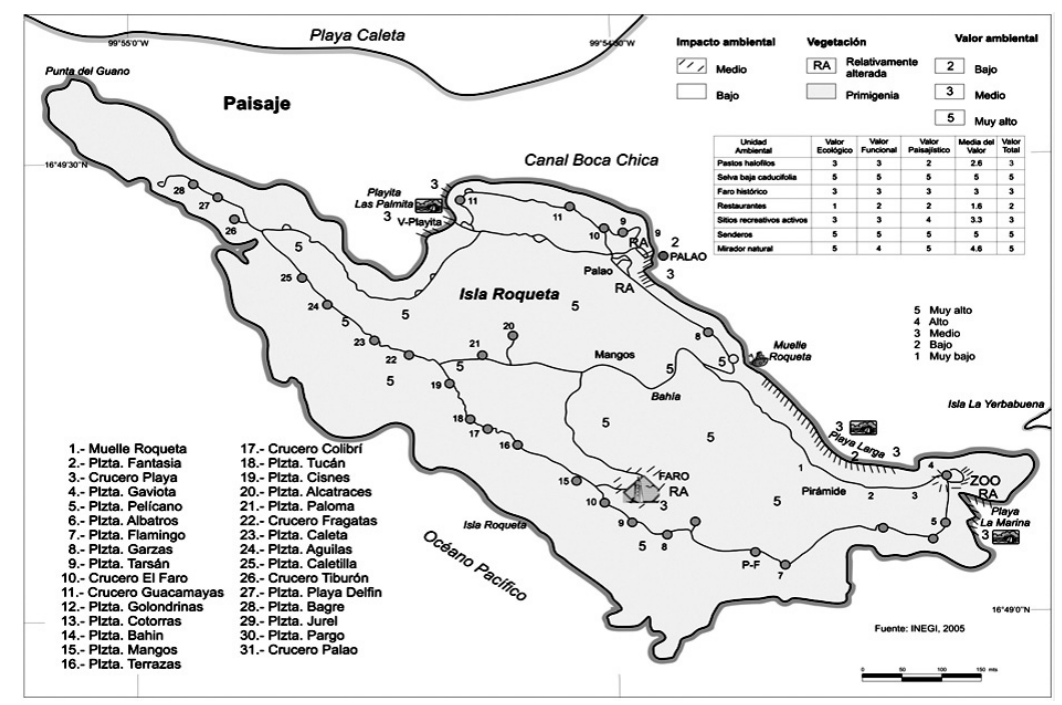

Fuente: INEGI, 2005. 
El significativo valor ambiental que representan los elementos vegetación, agua y suelo se hacen evidentes en el estatus actual de La Roqueta como UMA, ya que las unidades de selva baja caducifolia, senderos y mirador natural son vitales para conservar el paisaje natural de la isla. A continuación se muestran los valores de los componentes ambientales y sus interrelaciones (Tabla 1).

\begin{tabular}{|c|c|c|c|c|c|}
\hline $\begin{array}{c}\text { Unidad } \\
\text { Ambiental }\end{array}$ & Valor ecológico & Valor funcional & Valor paisajistico & Media del valor & Valor total \\
\hline Pastos halófilos & 3 & 3 & 2 & 2.6 & 3 \\
\hline $\begin{array}{c}\text { Selva baja } \\
\text { caducifolia }\end{array}$ & 5 & 5 & 5 & 5 & 5 \\
\hline Faro histórico & 3 & 3 & 3 & 3 & 3 \\
\hline Restaurantes & 1 & 2 & 4 & 3.3 & 3 \\
\hline $\begin{array}{c}\text { Sitios recreativos } \\
\text { activos }\end{array}$ & 3 & 3 & 5 & 5 & 5 \\
\hline Senderos & 5 & 5 & 5 & 4.6 & 5 \\
\hline Mirador natural & 5 & 4 & & & 2 \\
\hline
\end{tabular}

\section{Tabla 1}

Valor ambiental de La

Roqueta

Fuente: Elaboración propia. 


\section{CONCLUSIONES}

La isla de La Roqueta es un enclave geográfico único por su ubicación estratégica para arribar de alta mar hacia el continente donde es necesario atravesar la bahía de Santa Lucía, ostenta un clima tropical con lluvias en verano que permite el desarrollo de vegetación selvática donde a la fecha se protegen ceibas, amates y palo morado; además de diversos ejemplares de fauna algunos de ellos endémicos y otros en peligro de extinción; por ejemplo en el ecosistema marino se pueden citar a invertebrados como los crustáceos, moluscos, arrecifes coralinos y en menor grado quelonios (tortugas marinas migratorias y/o locales, tortugas de río y/o terrestres); en el ecosistema terrestre hay venados cola blanca, zopilote rey; a éstos les siguen los psitaciformes (cotorra serrana, guacamayas, loros y/o pericos) y reptiles escamosos como las Iguanas verdes $y$ negras.

El amalgamiento de atributos escénicos sumado a funciones ecológicas, preserva el ecosistema de selva baja caducifolia, valiosa por su riqueza en biodiversidad florística y faunística; estos atributos operan como importante zona de captación pluvial y elevada recarga acuífera manteniendo el equilibrio hidrológico regional, y coadyuvan a la regulación y estabilidad climática.

El conocimiento integral de las características geográficas, biodiversidad y otros atractivos paisajístico-escénicos aunado a los elementos socioeconómicos redundará en un mejor manejo administrativo de esta UMA de Acapulco, Guerrero, México. 


\section{BIBLIOGRAFÍA}

- Araujo, Elías (2003), Fauna Silvestre del Estado de Guerrero, Guerrero Cultural Siglo XXI, México.

- Aviléz, Hernando; Yolanda González; Ángeles Ignacio y Elvia Chavarría (2003), "EI impacto de la contaminación". En Turismo extremo. Revista científica turística. Número 1. Edición Bimensual. Acapulco, Guerrero, México. Diciembre. Pp. 30-33.

- Fabián, Eva y Alicia Escobar (2002), Geografía General, Mc Graw-Hill, México.

- García, Enriqueta (1987), Los climas de México, Porrúa, México.

- INEGI (2000), Ortofoto de la Bahía de Acapulco y su área de influencia, escala 1:20 000, México.

- INEGI (2004), Sistema para la consulta del Cuaderno estadístico municipal. Acapulco de Juárez, Guerrero 2004. México.

- INEGI (2005), Carta topográfica Acapulco E14C57, Escala 1:50 000, México.

- Martínez, Alejandro (1994), Memoria de Acapulco, H. Ayuntamiento Constitucional Acapulco de Juárez, 1993-1996, México.

- Melo, Carlos y Naú Niño (2006), "Las Áreas Naturales Protegidas Federales de México como reservorios de biodiversidad y otros recursos naturales" en: Ortiz Hernández María L. (Coord.), Memorias del XI Congreso Nacional y V Congreso Internacional en Ciencias Ambientales. México, Universidad Autónoma del Estado de Morelos.

- Niño, Naú (2007), "Los recursos naturales como sustento del ecoturismo en la isla Roqueta de Acapulco, Guerrero", Memorias en extenso del VI Congreso Internacional y XII Nacional de Ciencias Ambientales de la Academia Nacional de Ciencias Ambientales (ANCA) A. C. y la Universidad Autónoma de Chihuahua. Chihuahua, Chihuahua, México.

- UAG (2003), "Los vendedores ambulantes en las playas de Acapulco", En Turismo extremo. Revista científica turística. Número 1. Edición Bimensual. Acapulco, Guerrero, México. Pp. 6-20.

- Vidal, Rosalía (2005), Las regiones climáticas de México, Instituto de Geografía, UNAM, México. 


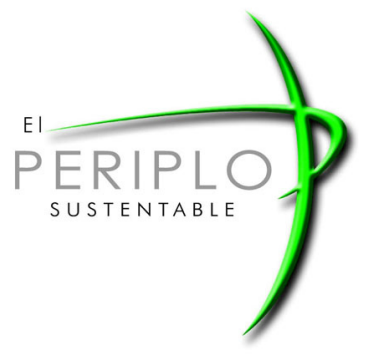

FICHA BIBLIOGRAFICA:

Niño-Gutiérrez, N. Ambiente de la isla Roqueta de Acapulco, Guerrero, México.

El Periplo Sustentable. Espacio de análisis y reflexión sobre Turismo Sustentable. México: Universidad Autónoma del Estado de México, julio de 2008, núm. 14

$<$ http://www.uaemex.mx/plin/psus/rev14/articulo_01.pdfs.

[ISSN: 1870-9036]. 